\title{
A EVOLUÇÃO POLÍTICA BRASILEIRA
}

\author{
Lucas Ferreira Furlan, Sérgio Mastellini \\ Universidade do Oeste Paulista - UNOESTE, curso de Direito, Presidente Prudente - SP. Email: \\ lucasfurlan94@hotmail.com
}

\section{RESUMO}

O presente artigo tem como objetivo realizar um convite à análise histórica de nossa evolução política ao longo do primeiro século da República. Este foi construído, utilizando-se pesquisas bibliográficas, leituras e fechamentos, para que, dessa forma, possamos conseguir entender os fatos que influenciaram a elaboração do gênese da atual Constituição Federal. Foi realizada uma análise concisa dos principais períodos pelos quais o país passou desde a proclamação da República, até o fim da ditadura militar, destacando-se os erros e acertos do passado, que influenciaram o constituinte da atual Carta da República, quando de sua elaboração, concluindo-se que os sucessivos governos autoritários que se alternaram no poder, no primeiro século da República, influenciaram para que esta possuísse um caráter extremamente garantista, no que se refere à tutela de liberdades públicas.

Palavras Chave: Debate, Congresso, Eleições, Constituição e República.

\section{THE EVOLUTION OF BRAZILIAN POLICY}

\begin{abstract}
This article aims to conduct an invitation to review the history of our political evolution during the first century of the Republic, using literature searches, lectures and closings, this was built, so this way we can understand the facts that influenced the preparation of the genesis of the current Federal Constitution. A concise analysis of the main periods in which the country was held passed since the proclamation of the Republic until the end of the military dictatorship, especially the rights and wrongs of the past, influencing the current Charter constituent of the Republic upon their preparation, concluding if that successive authoritarian governments that alternated in power in the first century of the Republic influenced so that it possessed an extremely garantista character with regard to the protection of civil liberties.
\end{abstract}

Keywords: Debate, Congress, Elections, Constitution and Republic. 


\section{INTRODUÇÃO}

É consenso que o Texto Republicano de 1988 foi uma Constituição à frente de seu tempo, tanto que passou a ser conhecida como "Constituição Cidadã", em virtude de sua atenção para com os direitos e garantias dos indivíduos e o fortalecimento das instituições. Isto, a nosso ver, sobre tudo se deve aos sucessivos períodos autoritários ou, mesmo, de mera democracia aparente, que o país enfrentou ao longo do primeiro século de sua República.

O objetivo deste artigo será a realização de um levantamento histórico-político do primeiro século republicano de nosso país, para que, assim, possamos descobrir qual foi o contexto histórico que influenciou o legislador constituinte de 1988 a elaborar um texto Constitucional, que, em muito, se preocupou com as garantias e liberdades individuais e sobre tudo com a solidificação das instituições democráticas.

\section{METODOLOGIA}

$\mathrm{O}$ artigo foi norteado por pesquisas bibliográficas, leituras e fichamentos. Os dados foram analisados com emprego do método hipotético-dedutivo, informações coletadas, analisadas e confrontadas de forma dialética.

\section{RESULTADOS}

Os resultados alcançados, com a presente pesquisa, foram concretos, de modo a contribuir, de forma racional e equilibrada, para a análise dos fatos políticos ao longo de nossa história Republicana.

\section{DISCUSSÃO}

\section{A República da Espada}

A República da Espada se iniciou com a eleição, pelo Congresso Nacional, dos Marechais Deodoro da Fonseca e Floriano Peixoto para os cargos de Presidente e Vice-Presidente da República respectivamente.

O governo de Deodoro da Fonseca foi marcado por constantes atritos com o Congresso e tentativas sucessivas de ampliação dos poderes do Presidente. Deodoro acreditava que somente um governo centralizador poderia conduzir o Brasil a um novo ciclo de desenvolvimento, mas isto confrontava, diretamente, com os interesses dos grandes latifundiários que comandavam o Congresso e queriam um governo descentralizador com mais autonomia para os Estados, para que, dessa forma, eles os pudessem comandar. 
Em sua obra, Hamilton M. Monteiro descreve o cenário em questão, (1990, p. 30):

Os meses de janeiro, fevereiro e março são marcados por denúncias de corrupção malversação do dinheiro público. A imprensa volta à carga, porém, agora não são somente os civis que criticam a ditadura de Deodoro; militares descontentes com os rumos do Governo também se pronunciam nos quartéis e em artigos nos jornais. As oposições divulgam boatos alarmistas, pregam cartazes nas cidades e distribuem panfletos.

Esse atrito de interesses resultou em um período turbulento, cheio de crises e, até, no fechamento do Congresso Nacional. A situação tornou-se critica, quando os militares se revoltaram contra o Presidente e este, isolado, não teve alternativa senão a de renunciar.

Neste cenário tempestuoso, o Marechal Floriano Peixoto assumiu a Presidência da República, fez uma aliança com o Partido Republicano Paulista, comandado pelas oligarquias cafeeiras, e, com isto, conseguiu dar ao governo uma fraca sustentação política. Floriano fez um governo duro, reprimiu, com firmeza, todas as revoltas que enfrentou e manteve o Congresso fechado na maior parte do tempo em que esteve no poder.

A aliança que Floriano fez com o PRP abriu caminho para a elite latifundiária assumir o poder assim que seu mandato terminasse e, com ele, o período da República da Espada, época de muitas revoltas e pouca participação popular.

\section{A República das Oligarquias}

Com a realização da primeira eleição para Presidente da República, o candidato dos cafeicultores paulistas, Prudente de Moraes, foi eleito para o cargo mais alto da República, representando, com isto, a chegada dos oligarcas latifundiários ao poder.

Prudente de Morais foi eleito com 276.583 votos contra 38.291 de seu principal competidor, Afonso Pena, em uma época na qual o Brasil tinha mais de 14 milhões de habitantes, números que demonstravam a clara exclusão da imensa maioria da população da vida democrática do país. Nas décadas que se seguiram a elite latifundiária passou deter em suas mãos, praticamente todo o poder político nacional.

Desde os tempos do Império, os latifundiários sonhavam com tomar o poder. Agora, tendo-o conseguido, eles precisavam de um meio seguro, para conseguir nele se manter. Coube, então, ao sucessor de Prudente de Moraes o também oligarca paulista Campos Sales, criar esse meio. Nascia um arranjo político, que tinha como objetivo evitar conflitos entre os governos estaduais e o governo central, garantindo a vitória dos grupos políticos mais fortes no interior dos estados. 
Funcionava da seguinte forma: as oligarquias dominantes, em cada Estado, apoiavam o governo central e, em troca, este não reconhecia a vitória dos candidatos oposicionistas para as Câmaras dos Estados. Para isto, foi criada a Comissão Verificadora de Poderes, que tinha como função verificar as atas de votação e cassar os direitos políticos dos candidatos da oposição que viessem a ter votos suficientes para ser eleitos.

Porém nem sempre a Comissão Verificadora de Poderes tinha muitos candidatos para cassar. Naquela época, o voto era aberto. Portanto, a maioria do eleitorado cedia a pressões exercidas por esses chefes políticos, e acabavam votando nos candidatos que Ihes eram indicados.

As oligarquias passaram, então, a comandar todos os governos estaduais e, também, o federal, como os latifundiários de São Paulo, produtores de café; e, de Minas Gerais produtores de leite, que eram os mais poderosos do país passaram a se revezar no poder central.

Este sistema de barganha política perdurou por longos trinta e seis anos. Por intermédio de meios, como pressões, subornos e assistencialismo; as famílias dos coronéis conseguiram manterse no poder, uma eleição após a outra, ou seja, existia um pleito e existia um eleito, mas a legitimidade deste, para exercer o poder republicano estatal, era totalmente questionável.

\section{A Revolução de 1930 e a Ditadura Vargas}

A atuação da Comissão Verificadora de Poderes e a força dos coronéis regionais, somada à exclusão da população das decisões políticas no país, conseguiram manter os latifundiários no poder por décadas. O sistema só veio a ruir, quando os paulistas, sob a liderança de Washington Luís, quiseram permanecer, por dois mandatos consecutivos, no poder, fato que gerou uma rebelião da elite mineira, que, com a ajuda das oligarquias do Rio Grande do Sul e da Paraíba, lançou uma candidatura de oposição encabeçada pelo então governador do Rio Grande do Sul, Getúlio Vargas.

O levante feito pelos mineiros não surtiu efeito e o candidato dos coronéis paulistas, Júlio Prestes, acabou saindo vitorioso da eleição. Entretanto um fato imprevisível favoreceu os oligarcas oposicionistas: devido a conflitos regionais, o candidato a vice, na chapa de Getúlio Vargas, o paraibano João Pessoa, foi assassinado. Os oposicionistas decidiram, então, utilizar esse ato a seu favor, organizando uma ação armada contra o então presidente paulista Washington Luís.

Tendo inicio em Minas Gerais e no Rio Grande do Sul, o movimento rapidamente se espalhou pelo nordeste, tornando insustentável a permanência do Presidente no poder. Pressionado pelos militares, este não teve alternativa, se não renunciar. Os militares ocuparam, provisoriamente, o governo e o Brasil se aproximava de sua primeira ditadura. 
Apoiado pelos oligarcas e pelo exército, Getúlio Vargas assumiu o governo em três de novembro de 1930. De início, Vargas comandaria apenas um governo transitório, até que novas eleições fossem convocadas. Mas não foi isto que ocorreu.

Durante o governo provisório de Getúlio Vargas, uma nova Assembléia Nacional Constituinte foi convocada, sendo promulgada, em 1934, a nova Constituição, a qual estabelecia que Getúlio ficasse no poder, até 1938 , ano em que seria convocada a nova eleição para Presidente da República.

Todavia isto não estava nos planos de Vargas e seus aliados. "Getúlio Vargas tinha uma postura dúbia. Publicamente defendia a realização das eleições. Nos bastidores, preparava um golpe para permanecer no poder." (EDITORA MODERNA, 2006, p. 138). Com a proximidade das eleições, Getulio se aliou aos militares e só esperava uma oportunidade, para dar o golpe que instituiria a ditadura no país. Alegando uma fantasiosa ameaça comunista, Getúlio tomou o poder em 10 de novembro de 1937. O exercito fechou o Congresso Nacional e, no mesmo, dia Getúlio anunciou, pelo rádio, a implantação do Estado Novo.

Depois disto, os partidos políticos foram fechados, os governadores de Estados, destituídos e substituídos por interventores, todos os direitos democráticos foram suspensos. E, ainda em 1937, uma nova Constituição foi outorgada, dando poderes quase que imperiais ao Presidente. Vargas passou a centralizar, em suas mãos, todos os poderes, podendo desde nomear os governadores dos Estados, até interferir no Judiciário. A imprensa foi censurada e duramente perseguida. Até 1945, o Brasil viveu um dos períodos mais autoritários de sua história.

Getúlio soube como ninguém, estabelecer uma comunicação com as massas populares. Passando a imagem de líder preocupado com o bem-estar de seu povo Vargas conseguiu grande apoio popular, sobretudo dos menos escolarizados e marginalizados. E assim, como esses grupos formavam a imensa maioria da sociedade, Vargas possuía amplo apoio popular, mesmo sendo um ditador.

Ao final da Segunda Guerra Mundial, diversas ditaduras caíram pelo mundo, deixando a situação de Vargas praticamente insustentável. Ficava cada vez mais difícil para o ditador explicar como o Brasil lutou, na Europa, contra ditaduras mesmo estando em uma.

A oposição ao governo passou a cobrar mudanças, a elite mineira expediu um manifesto, exigindo o fim da ditadura, manifesto que se tornou a primeira manifestação pública contrária ao Estado Novo. Em 1945, pressionado pelos militares, Vargas se viu sem saída e renunciou. 


\section{A Terceira República}

Terminada a Ditadura de Getúlio Vargas, o Brasil viveu um período de aparente estabilidade democrática. Contudo essa estabilidade não duraria nem dez anos. No dia 31 de março de 1964, os militares tomariam o poder e se iniciaria o maior período ditatorial da história de nosso país. A seguir, estudaremos como isto ocorreu.

O último presidente eleito democraticamente, neste período, o paulista Jânio Quadros, subiu a rampa do Planalto com ares de salvador da pátria, mas não foi nem de longe, isto. Jânio fez uma campanha, falando para as classes mais escolarizadas do país. Desse modo, com discursos exaltados sobre combate à corrupção, posando de administrador ousado, Jânio venceu fácil, a eleição, porém com um problema que posteriormente lhe aparentaria solução.

A constituição de 1946 havia estipulado que os eleitores votariam não somente para Presidente mais também para Vice-Presidente, podendo, inclusive, escolher candidatos de chapas distintas. E foi justamente o que ocorreu em 1960: o candidato do UND foi eleito Presidente (Janio Quadros), mais foi o candidato da chapa PSD/PTB (João Goulart), que foi escolhido VicePresidente.

Para muitos, isto seria uma catástrofe, mas, para Janio, isto logo se tornaria solução, para por em prática, seu projeto de poder. Passados apenas sete meses de governo, Janio anunciou a decisão impensável: simplesmente renunciou à presidência. Mas logo o plano do presidente ficou claro: com sua renúncia, o cargo, por direito, passaria ao vice-presidente João Goulart, que era simplesmente detestado por toda a direita, os militares e o empresariado.

Jânio esperava que o povo logo implorasse por sua volta, e, como o vice-presidente era mal visto por parte da classe política, ele acreditava conseguir negociar sua volta ao cargo, com um aumento significativo dos poderes presidenciais.

Em sua obra, Nova História Crítica o autor Mario Schmidt, descreve o cenário em estudo, (2008, p. 647):

A renúncia significava uma verdadeira chantagem contra esses grupos poderosos: "Vocês querem que eu saia? Seu eu sair, olha só quem assume: o Jango!" Ora, diante desse quadro, ele apostava que os militares, burgueses políticos conservadores suplicariam para que se mantivesse à testa do Estado. Então, Jânio poderia anunciar os termos da barganha política: "Fico, mas sob minhas condições."

Porém Janio fez uma análise errada da conjuntura política: o povo não pediu que ele voltasse e a classe política conseguiu costurar um acordo com a direita e o militares para que o vice-presidente pudesse assumir a Presidência, o Brasil se tornaria uma República Parlamentarista. 
Os militares estavam exigindo que os poderes do Presidente fossem limitados, caso contrario não permitiriam a posse; o governador do Rio Grande do Sul (Leonel Brizola) ameaçava pegar em armas para garantir que o Vice-Presidente assumisse a Presidência; o país beirava à guerra civil. Quando a situação chegou ao limite, os congressistas deram a solução, aprovando a emenda parlamentarista, o Congresso passou a se chamar "Parlamento do Brasil" e o chefe de governo passou a ser o primeiro-ministro. Jango assumiu, mas com poderes limitados.

O parlamentarismo durou pouco. Implantado em 1961, foi rejeitado no plebiscito de 1963 por um resultado que chegou a incríveis 10 votos a 1 para o presidencialismo. Jango agora tinha em mãos todos os poderes da Presidência, mas seria por poucos meses.

Pela sua história política, podemos concluir que João Goulart era um homem de direita, mas seus discursos e atitudes no exercício da presidência se alinhavam muito com a esquerda. Isso somado ao clima de Guerra-Fria que o mundo enfrentava, serviu para deixar o país sempre com um golpe à iminência.

Em uma suposta tentativa de modernizar o capitalismo brasileiro, o Presidente propôs diversas reformas, visando diminuir as desigualdades sociais do país, porém os setores conservadores da sociedade as interpretaram como uma ameaça comunista.

Sabendo que não conseguira passar as reformas pelo Congresso Nacional o Presidente começou instituí-las por Decreto. No famoso comício da Central do Brasil, onde centenas de milhares de pessoas compareceram, Goulart anunciou as suas primeiras reformas, como a expropriação dos latifúndios improdutivos e a nacionalização das refinarias de petróleo.

A resposta da direita foi uma manifestação que levou milhares de pessoas às ruas de São Paulo. Os ânimos entre a direita e a esquerda estavam cada vez mais exaltados. A gota d' água foi quando o Presidente decidiu anistiar marinheiros que tinham se revoltado contra seus comandantes: os oficiais do exercito consideraram o ato uma afronta. A reação foi instantânea. No dia 31 de março de 1964, tropas partiram de Minas Gerais com destino ao Rio de Janeiro, onde se encontrava Goulart. O Presidente ainda tentou ir a Brasília para comandar a resistência, mas não havia mais o que ser feito: o golpe estava dado.

\section{A Ditadura Militar}

A Ditadura Militar é hoje o período de exclusão da sociedade do debate político nacional mais lembrado e debatido. Em todas as campanhas presidenciais desde a redemocratização, os presidenciáveis têm a necessidade de mostrar seu engajamento na luta pelo fim deste terrível 
regime, como se o período de repressão e exclusão da sociedade do poder se resumisse àqueles vinte e quatro anos.

Talvez o fato de os meios de comunicação serem mais fortes e eficientes nos anos sessenta tenha feito o fechamento do Congresso Nacional soar de uma forma muito mais absurda do que soou durante a República da Espada ou a implantação do Estado Novo.

Pode ser que como os adversários do regime chegaram ao poder logo após o seu término, as perseguições e torturas cheguem hoje aos nossos ouvidos de uma forma muito mais impactante do que a atuação da Comissão Verificadora de Poderes durante a República das Oligarquias.

Quem sabe a ausência de medidas populistas por parte dos Presidentes militares faça com que o fim das eleições para governador e presidente pareça muito mais absurdo que a nomeação de interventores durante a Ditadura Vargas.

É provável que como os veículos de comunicação censurados pelo Regime Militar perdurem até hoje, nos pareça que o Al5 foi uma abominação legal infinitamente maior que a Constituição de 1937, que também extinguiu a democracia no Brasil.

É possível que aquele que faça uma leitura de forma superficial apenas da introdução deste tópico pense que a intenção é a de defender a ditadura; nem de longe a foi, mas sim a de demonstrar que ela a muito se assemelha com outros tempos também vividos por nosso país. Como ocorreu com a República da Espada, onde o Congresso Nacional também foi fechado, a República das Oligarquias quando as eleições até existiam, mas eram fraudadas, e o Estado Novo época em que os inimigos do governo igualmente foram perseguidos.

Em resumo, a Ditadura Militar foi só uma reedição mais dura das práticas já aplicadas durante os períodos de repressão anteriores. Com o Movimento das Direitas Já, realizado no fim do regime, os cidadãos pareciam enfim ter se rebelado contra esse sistema, e passaram a exigir participação popular legítima no sistema político nacional.

\section{CONCLUSÃO}

Após a realização deste estudo fica claro que o nosso primeiro século Republicano foi sem dúvida um período instável, onde diversos tipos de governos autoritários se alternaram no poder, hoje sem duvida o país conta com instituições políticas fortes, graças à atual Constituição Federal.

Concluímos que o artigo conseguiu cumprir com aquilo que se propôs, ao apresentar de forma clara e concisa os principais fatos políticos de nossa história que influenciaram o constituinte da atual Constituição Federal. 
É para nos evidente que a sucessão de governos autoritários que passaram pelo país no passado, em muito influenciou na elaboração da atual Carta da Republica, fazendo com que esta seja conhecida como "Constituição Cidadã", em virtude de sua preocupação com a solidificação das instituições democráticas e liberdades individuais.

Será fundamental que levantamentos como estes sejam refeitos para que dessa forma, como já dito acima, o país possa aprimorar o que é correto e corrigir os erros, considerando o que ocorreu no passado.

\section{REFERÊNCIAS}

EDITORA MODERNA. A era vargas. In: EDITORA MODERNA. Projeto araribá história. 1. ed. São Paulo: Moderna, 2006. cap. 5, p. 134-158.

EDITORA MODERNA. A república chega ao Brasil. In: EDITORA MODERNA. Projeto araribá história. 1. ed. São Paulo: Moderna, 2006. cap. 2, p. 44-72.

EDITORA MODERNA. Democracia e ditadura no Brasil. In: EDITORA MODERNA. Projeto araribá história. 1. ed. São Paulo: Moderna, 2006. cap. 7, p. 190-218.

MONTEIRO, M. H. Brasil república. 2 ed. São Paulo: Ática, 1990.

SCHMIDT, M. F. A era Vargas. In: SCHMIDT, M. F. Nova história crítica. 1. ed. São Paulo: Nova Geração, 2005. cap. 46, p. 552-575.

SCHMIDT, M. F. República. In: SCHMIDT, M. F. Nova história crítica. 1. ed. São Paulo: Nova Geração, 2005. cap. 39, p. 456-470.

SCHMIDT, M. F.República velha. In: SCHMIDT, M. F. Nova história crítica. 1. ed. São Paulo: Nova Geração, 2005. cap. 41, p. 482-501. 